\title{
Insulitis and characterisation of infiltrating $T$ cells in surgical pancreatic tail resections from patients at onset of type 1 diabetes
}

\author{
Lars Krogvold $^{1,2}$ • Anna Wiberg ${ }^{3}$ - Bjørn Edwin ${ }^{2,4}$ - Trond Buanes ${ }^{2,5}$. \\ Frode Lars Jahnsen ${ }^{6,7} \cdot$ Kristian F. Hanssen ${ }^{2,8} \cdot$ Erik Larsson $^{3}$ • Olle Korsgren ${ }^{3}$. \\ Oskar Skog $^{3} \cdot$ Knut Dahl-Jørgensen ${ }^{1,2}$
}

Received: 13 July 2015 / Accepted: 3 November 2015 / Published online: 24 November 2015

(C) Springer-Verlag Berlin Heidelberg 2015

\begin{abstract}
Aims/hypothesis It is thought that $\mathrm{T}$ cells play a major role in the immune-mediated destruction of beta cells in type 1 diabetes, causing inflammation of the islets of Langerhans (insulitis). The significance of insulitis at the onset of type 1 diabetes is debated, and the role of the T cells poorly understood.

Methods In the Diabetes Virus Detection (DiViD) study, pancreatic tissue from six living patients with recent-onset type 1 diabetes was collected. The insulitis was characterised quantitatively by counting $\mathrm{CD}^{+} \mathrm{T}$ cells, and qualitatively by transcriptome analysis targeting $84 \mathrm{~T}$ and $\mathrm{B}$ lymphocyte genes of laser-captured microdissected islets. The findings were compared with gene expression in T cells collected from kidney biopsies from allografts with ongoing cellular rejection. Cytokine and chemokine release from isolated islets was characterised and compared with that from islets from nondiabetic organ donors.
\end{abstract}

Lars Krogvold and Anna Wiberg contributed equally to the study and are listed in alphabetical order.

Knut Dahl-Jørgensen and Oskar Skog are joint senior authors.

Knut Dahl-Jørgensen is Principal Investigator of the DiViD study.

Electronic supplementary material The online version of this article (doi:10.1007/s00125-015-3820-4) contains peer-reviewed but unedited supplementary material, which is available to authorised users.

Lars Krogvold

lars.krogvold@gmail.com

1 Paediatric Department, Oslo University Hospital HF, PO Box 4950, Nydalen, N-0424 Oslo, Norway

2 Faculty of Medicine, University of Oslo, Oslo, Norway

3 Department of Immunology, Genetics and Pathology, Uppsala University, Uppsala, Sweden
Results All six patients fulfilled the criteria for insulitis (5-58\% of the insulin-containing islets in the six patients had $\geq 15$ $\mathrm{T}$ cells/islet). Of all the islets, $36 \%$ contained insulin, with several resembling completely normal islets. The majority (61$83 \%$ ) of T cells were found as peri-insulitis rather than within the islet parenchyma. The expression pattern of $\mathrm{T}$ cell genes was found to be markedly different in islets compared with the rejected kidneys. The islet-infiltrating $\mathrm{T}$ cells showed only background levels of cytokine/chemokine release in vitro. Conclusions/interpretation Insulitis and a significant reserve reservoir for insulin production were present in all six cases of recent-onset type 1 diabetes. Furthermore, the expression patterns and levels of cytokines argue for a different role of the $\mathrm{T}$ cells in type 1 diabetes when compared with allograft rejection.

Keywords Gene expression · Inflammation · Insulin · Insulitis $\cdot$ Pancreas $\cdot$ T cells $\cdot$ Type 1 diabetes

4 The Intervention Centre, Oslo University Hospital, Oslo, Norway

5 Department of Surgery, Division of Cancer, Surgery and Transplantation, Oslo University Hospital, Oslo, Norway

6 Department of Pathology, Oslo University Hospital, Oslo, Norway

7 Centre for Immune Regulation, University of Oslo, Oslo, Norway

8 Department of Endocrinology, Oslo University Hospital, Oslo, Norway 


$\begin{array}{ll}\text { Abbreviations } \\ \text { DiViD } & \text { Diabetes Virus Detection (study) } \\ \text { GRO } & \text { CXC chemokines growth-regulated oncogene } \\ \text { ICI } & \text { Insulin-containing islet } \\ \text { IDI } & \text { Insulin-deficient islet } \\ \text { IEQ } & \text { Standard islet equivalent } \\ \text { IP-10 } & \text { Interferon } \gamma \text { inducible protein } 10 \\ \text { LCM } & \text { Laser-capture microdissection } \\ \text { MCP-1 } & \text { Monocyte chemotactic protein } \\ \text { RPKM } & \text { Reads per kilobase per million mapped reads } \\ \text { TCR } & \text { T cell receptor }\end{array}$

\section{Introduction}

Type 1 diabetes is a disease characterised by a progressive loss of insulin-producing beta cells. A model for the natural history of type 1 diabetes, originally published by Eisenbarth in 1986 [1], suggests that the disease is triggered by one or several environmental factors in genetically susceptible individuals. The model has been modified and expanded [2]. The degree of beta cell destruction required to develop type 1 diabetes has been shown to depend on individual factors, such as age, BMI and physical activity [3]; in adults it has been predicted that as many as $40-50 \%$ of beta cells remain at the time of diagnosis [4].

Histologically, a discrete inflammatory infiltration of the islets of Langerhans is found in about $68 \%$ of children and $29 \%$ of young adults when examined within 1 month of diagnosis [5]. This lesion, first described in a diabetic child who died from ketoacidosis [6], was later named insulitis [7]. Insulitis, together with the presence of circulating autoantibodies directed against islet cell antigens, has been regarded as evidence for an immunemediated aetiology of type 1 diabetes [1]. The infiltrating cells may be found in the islet-exocrine interface, when it is called peri-insulitis, or be present within the islet parenchyma, in which case it is called intra-insulitis [8]. The lesions mainly affect islets containing insulin-producing cells and, according to a recent consensus report, should be present in a minimum of three islets, with a threshold level of $\geq 15 \mathrm{CD} 45^{+}$cells/islet to be classified as insulitis [8]. Surprisingly, since 1902 only a total of 48 out of 247 examined cases of type 1 diabetic patients with insulitis (according to the previous definition of insulitis, demanding $\geq 5 \mathrm{~T}$ cells/islet) have been described in the literature [5].

The objective of the Diabetes Virus Detection (DiViD) study was to collect pancreatic tissue from clinically wellcharacterised patients with type 1 diabetes soon after the diagnosis. The sampling procedures and clinical data, including autoantibody titres and HLA haplotypes, have been reported previously [9]. Here, we report on the degree of T cell inflammation in endocrine and exocrine tissue and characterise the islet-infiltrating cells using laser-capture microdissection (LCM) and transcriptome analysis targeting $84 \mathrm{~T}$ and $\mathrm{B}$ lymphocyte genes. The findings were compared with $\mathrm{T}$ cells collected from biopsies of kidney allografts with ongoing cellular rejection (Banff 1A and 1B). Furthermore, cytokine and chemokine release from isolated islets is characterised and compared with that from islets of non-diabetic organ donors.

\section{Methods}

A total of six patients, aged 24-35 (median 28) years were recruited to the study. Pancreatic biopsies, consisting of approximately $3 \mathrm{~cm}$ of the tail of each pancreas, were laparoscopically taken 3-9 weeks after diagnosis of type 1 diabetes (median 5 weeks). The surgery was performed under general anaesthesia; it involved a standard spleen-preserving procedure with dissection of the pancreatic tail and the splenic vein before division of the tail from the pancreatic body with an endoscopic GIA-stapler (Medtronic, Minneapolis, MN, USA). The clinical details of the patients have been reported previously $[9,10]$. Pancreatic tissue from three non-diabetic organ donors of normal weight, matched for age (20,22 and 25 years), and kidney graft biopsies from two patients with ongoing cell-mediated allorejection were used as controls for the gene-expression analysis. The kidney transplant rejections were classified as Banff 1A (recipient HLA: A1,A2 B8,B60, DRB1*03,DRB1*11, DQB1*02,DQB1*03; donor HLA: A2,A2 B3,B60, DRB1*03,DRB1*11, DQB1*02, $\mathrm{DQB} 1 * 03)$ and $1 \mathrm{~B}$ (recipient HLA: A1,A2 B18,B39 DRB1*01,DRB1*08, DQB1*05,DQB1*04; donor HLA: A2, A32, B15,B44, DRB1*04,DRB1*15, DQB1*03,DQB1*06) respectively, and occurred after immunosuppression with ciclosporin A and prednisolone was switched to tacrolimus, mycophenolate mofetil and prednisolone (patient with Banff 1A), and tacrolimus and prednisolone (patient with Banff 1B). Islets isolated from six donors (mean age 58 years [range 54-61 years], BMI $26.6 \mathrm{~kg} / \mathrm{m}^{2}$ [range $24.6-31.1 \mathrm{~kg} / \mathrm{m}^{2}$ ]) were used as controls for the analysis of cytokines and chemokines. In order to run the case and control islets in parallel, islets from unmatched donors that were available for research at the time were used. Collection of pancreatic tissue in the DiViD study was approved by the Norwegian Governments Regional Ethics Committee. Written informed consent was obtained from all individuals with type 1 diabetes after they had received oral and written information from the diabetologist and the surgeon separately. Ethics permission for using kidney biopsies for research was approved by the Regional Ethics Committee in Uppsala (Dnr 2011/349/2). Consent for using isolated islets and pancreatic tissue for research was obtained verbally from the deceased person's next of kin by the attending physician and was documented in the medical records of the deceased person in accordance with Swedish law and as approved by the Regional Ethics Committee (Dnr 2009/043 and 2009/371).

The pancreatic biopsies from type 1 diabetic patients were processed as described previously [10]. Sections, $4 \mu \mathrm{m}$, from 
two different paraffin blocks for each of the six patients were processed and labelled using a standard immunoperoxidase technique. Double immunostainings were performed on three consecutive sections from each block: anti-CD3 (rabbit antibody, dilution 1:150, Neomarkers, Fremont, CA, USA)/insulin (mouse antibody, clone 2D11/H5, dilution 1:100, Novocastra, Newcastle upon Tyne, UK), anti-CD3/glucagon (rabbit antibody, clone EP74, dilution 1:400, Epitomics, Burlingame, CA, USA) and insulin/glucagon. This gave a total of 36 sections ( 6 cases $\times 2$ blocks $\times 3$ stainings). Slides were counterstained with haematoxylin and analysed by light microscopy. The total number of islets was registered by counting glucagon-containing islets. Only islets containing at least five to ten endocrine cells were registered, while single glucagon- or insulin-positive cells scattered in the exocrine area were not. Insulin-containing islets (ICIs) were counted and their area estimated using an ocular grid consisting of 100 squares of $0.0016 \mathrm{~mm}^{2}$ at a magnification of $\times 200$. For each ICI, the numbers of $\mathrm{CD}^{+}$cells within the islet area (intra-insulitis) and in the endocrine-exocrine interface in close contact with the islet boundary (peri-insulitis) were counted and registered. Regarding the latter, cells in direct contact with an islet or in contact with another $\mathrm{CD}^{+}$cell in direct contact with an islet were registered. The new definition for insulitis was used, meaning that the islet should contain or be closely surrounded by $\geq 15$ leucocytes $\left(\mathrm{CD} 45^{+}\right.$cells) to be considered insulitic, but with the modification that only T cells $\left(\mathrm{CD}^{+}\right)$were counted. By combining the three double immunostainings described, the percentage of four categories of islets [11], indicating the progress of disease, was calculated: A, ICIs without insulitis; B, ICIs with insulitis; C, insulindeficient islets (IDIs) with insulitis; and D, IDIs without insulitis.

To normalise the number of $\mathrm{CD}^{+}$cells per islet to a standard islet equivalent (IEQ), the islet area was divided by the area of an average cross-section of an IEQ. In the field of islet isolation and in the consensus statement on insulitis [8] an IEQ is defined as an islet of $150 \mu \mathrm{m}$ diameter, giving an average standard cross-sectional area of $0.010936 \mathrm{~mm}^{2}$ $\left(D_{\text {cross-section }}=[\pi / 4] \times D_{\text {Sphere, }}\right.$ where $\mathrm{D}=$ diameter $)$. As the consensus definition of insulitis does not take into account the huge variation in islet size, leading to underestimation of inflammation in small islets and vice versa, we propose a normalisation to allow accurate comparisons between different studies. To estimate insulin area and $\mathrm{CD}^{+}$cell density in exocrine tissue, 15 grids constituting a total area of $2.4 \mathrm{~mm}^{2}$ were randomly placed in each section and analysed by registering the content in each of the $(121 \times 15) 1,815$ intersections.

Laser-capture microdissection Frozen pancreatic samples from the individuals with type 1 diabetes, the three nondiabetic organ donors and needle biopsies from rejected kidneys were prepared for LCM, essentially as described in Marselli et al and Skog et al $[12,13]$. Sections mounted on
Superfrost Plus glass slides (Menzel-Gläser, Braunschweig, Germany) and stained for CD3 (rabbit anti-human CD3, Dako, Glaustrup, Denmark), as described previously [14], were used to identify and localise infiltrating T cells in islets and in the rejected kidneys. Sections mounted on Arcturus PEN Membrane Glass Slides (Life Technologies, Carlsbad, CA, USA), and consecutive to the sections stained for $\mathrm{CD} 3$, were used for LCM. Only islets with insulitis ( $\geq 15 \mathrm{CD}^{+}$cells) were microdissected and pooled. Islets without insulitis from the three non-diabetic organ donors and renal cortex from rejected kidneys with infiltrating T-cells were used as control. An Arctururs $^{\mathrm{XT}}$ instrument with HS LCM Caps (Life Technologies) was used for LCM.

RNA isolation and expression analysis from microdissected tissue Total RNA was isolated from the microdissected tissue using RNeasy Micro Kit (Qiagen, Sollentuna, Sweden). Synthesis and pre-amplification of cDNA were performed with the RT2 PreAMP cDNA Synthesis Kit (Qiagen) using a pathway-specific primer mix (Human T-Cell \& B-Cell Activation, PBH-053Z, Qiagen) according to the manufacturer's instructions. Expression analysis was performed using the RT2 Profiler PCR array for human T cell and B cell activation (PAHS-053Z) on a StepOne Plus instrument (Life Technologies). Beta actin (ACTB) and glyceraldehyde 3phosphate dehydrogenase (GAPDH) were chosen for normalisation as they are commonly used reference genes in human islets and display little variation between samples. To compare expression levels in immune cells from infiltrated islets and infiltrated kidney, PTPRC (CD45) was used for normalisation. All samples passed the quality control of PCR array reproducibility, reverse transcription control and genomic DNA contamination provided by the PCR array analysis software available at www.SABiosciences.com/pcrarraydataanalysis.php. The mRNA expression for each gene was normalised to the expression the reference genes using the $\Delta \mathrm{C}_{\mathrm{t}}$ method and the data are presented as relative expression representing $2^{-\Delta \mathrm{Ct}}$.

Islet isolation Islets from the individuals with type 1 diabetes and non-diabetic controls were isolated as described previously $[13,15]$. Islets from the controls were isolated from the entire pancreas with the aim of clinical transplantation and were available for research only because the islet yield was too low.

Cytokine/chemokine analysis Islets (100 handpicked) from the individuals with type 1 diabetes and six non-diabetic controls were analysed 1 day after isolation for cytokine/ chemokine content by Luminex xMAP (Millipore, Billerica, MA, USA). Each sample was lysed in $1 \mu 1$ cell lysis factor QG and $89 \mu$ l lysis buffer (Bio-Plex Pro, BioRad, Hercules, CA, USA), containing $\times 1$ protease inhibitor (SIGMAFAST, Sigma-Aldrich, St Louis, MO, USA) and sonicated for $20 \mathrm{~s}$. 
The lysate was centrifuged at $15,000 \mathrm{~g}$ for $10 \mathrm{~min}$ at $4^{\circ} \mathrm{C}$, the supernatant fractions filtered through Pierce DetergentRemoval spin columns (Thermo Scientific, Rockford, IL, USA) and the protein concentrations were determined by Bradford assay (Thermo Scientific). From each sample, $5 \mu \mathrm{g}$ total protein was used. Cytokines and chemokines were analysed with the HCYTMAG-60K-PX41 Milliplex kit (Millipore). The procedure described in the manual (HCYTOMAG-60K Rev.07-JUN-2012) was followed except for the volume of beads, detection antibodies and streptavidinphycoerythrin $(12.5 \mu \mathrm{l}$ instead of $25 \mu \mathrm{l}$ as described). The analysis was performed on a Magpix platform (Luminex, Austin, TX, USA).

Whole transcriptome sequencing Samples of RNA were extracted from isolated islets from individuals with type 1 diabetes and three non-diabetic controls and whole transcriptome sequencing was performed and analysed as described previously [13]. Normalised reads per kilobase per million mapped reads (RPKM) for the genes encoding the cytokines and chemokines included in the Luminex analysis are presented in this study and the full data set (reads) has been openly available in the BILS DOI repository (http://doi.bils.se/) under doi: 10.17044/BILS/g000002.

Statistical analysis Differences between group pairs were analysed by Wilcoxon matched-pairs signed rank test, or between groups by the Mann-Whitney test, using GraphPad Prism v6 (La Jolla, CA, USA). Findings were considered statistically significant at $p<0.05$.

\section{Results}

Insulin content Figure 1 shows the distribution of islets in the different categories in the 12 sections examined. On average, $36 \%$ of all islets investigated $(n=1,596)$ contained insulin, either with or without signs of insulitis. Of these ICIs, $74.2 \%$ did not seem to be affected by the disease, resembling completely normal islets. In some areas of the pancreatic biopsies the insulin-positive area was completely normal. Large variations were observed in the percentage of ICI, both between individuals (18-66\%) and between sections from different formalin-fixed blocks from the same individual $(0-94 \%$ in case 6$)$. The insulin area comprised, on average, $0.58 \%$ of the pancreatic tissue $(0.44-1.2 \%)$.

Insulitis and infiltrating $\mathbf{T}$ cells All six patients fulfilled the criteria for insulitis [8]. The variation between the cases was large. Only 6 of $130(5 \%)$ ICIs were affected in case $6(\geq 15$ $\mathrm{CD}^{+}$cells) vs 42 of $73(58 \%)$ in case 1 (Table 1$)$. There was also large variation in the mean total number of $\mathrm{CD}^{+}$cells per ICI (peri- and intra-insulitis), ranging from 2.2 in case 6 to

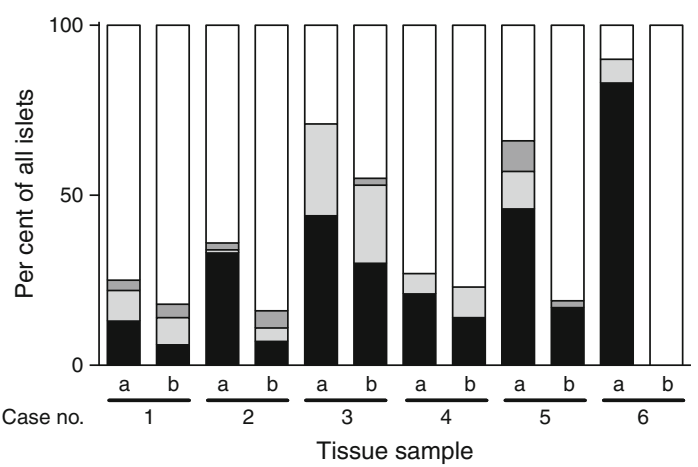

Fig. 1 Histological analysis of all islets in two pancreatic sections (a and b) from each of the six individuals with recent-onset type 1 diabetes. The islets were categorised as ICI or IDI with or without insulitis. Insulitis was defined as $\geq 15 \mathrm{CD}^{+}$cells in or in close association with the islet. Black, ICI without insulitis; light grey, ICI with insulitis; dark grey, IDI with insulitis; white, IDI without insulitis

31.6 in case 1 (Table 1). Although normalisation of the number of $\mathrm{CD}^{+}$cells to the size of an IEQ $(150 \mu \mathrm{m}$ diameter $)$ changed the number of $\mathrm{CD}^{+}$cells in individual islets by altering the denominator in the fraction, the mean number of $\mathrm{CD}^{+}$cells per islet and the fraction of insulitic islets per case remained basically the same (Table 1).

In total, $11 \%$ of all islets were infiltrated with $\geq 15 \mathrm{CD}^{+}$ cells. Most of the inflamed islets, $82 \%$, were ICIs. Again, large inter-individual (4-26\%) and intra-individual (2-20\% in case 5) variations were observed (Fig. 1). Of the ICIs, in total $25.8 \%$ showed insulitis. In contrast, insulitis affected only $2.9 \%$ of IDIs.

A significantly higher density of $\mathrm{CD}^{+}$cells was found in ICIs $\left(328 \pm 232\right.$ per $\left.\mathrm{mm}^{2}\right)$ than in exocrine tissue $(51 \pm 27$ per $\left.\mathrm{mm}^{2}\right)(p<0.05$, Fig. 2). They were found more frequently in the periphery of the islet (peri-insulitis) than within the islet area (intra-insulitis) (Table 1 and Figs 3 and 4). This difference was significant $(p<0.001)$ in all cases, but the fraction of total islet-associated $\mathrm{CD}^{+}$cells located inside the islets varied from only $17 \%$ in case 3 to $39 \%$ in case 4 (Table 1). As the islets of Langerhans constitute only $1-2 \%$ of the pancreas, in absolute numbers most of the $\mathrm{CD}^{+}$cells were located in the exocrine tissue.

Expression analysis of infiltrating cells of the $84 \mathrm{~T}$ and $\mathrm{B}$ cell genes studied, all except TLR1, CXCR3, TNFSF14, CD5 and TLR 9 were expressed $\left(\mathrm{C}_{\mathrm{t}}<35\right)$ in the infiltrated islets from at least two of the six patients. Islets from non-diabetic control donors had no or low expression of all genes analysed, except CD47, DPP4, CD81, CD276, TGFB1, MAP3K7 and NCK1. Since these genes were expressed in control islets that did not contain lymphocytes, they were excluded from further analysis (electronic supplementary material [ESM] Fig. 1). When compared with the expression pattern in islets from those with cell-mediated kidney allograft rejection, the immune 


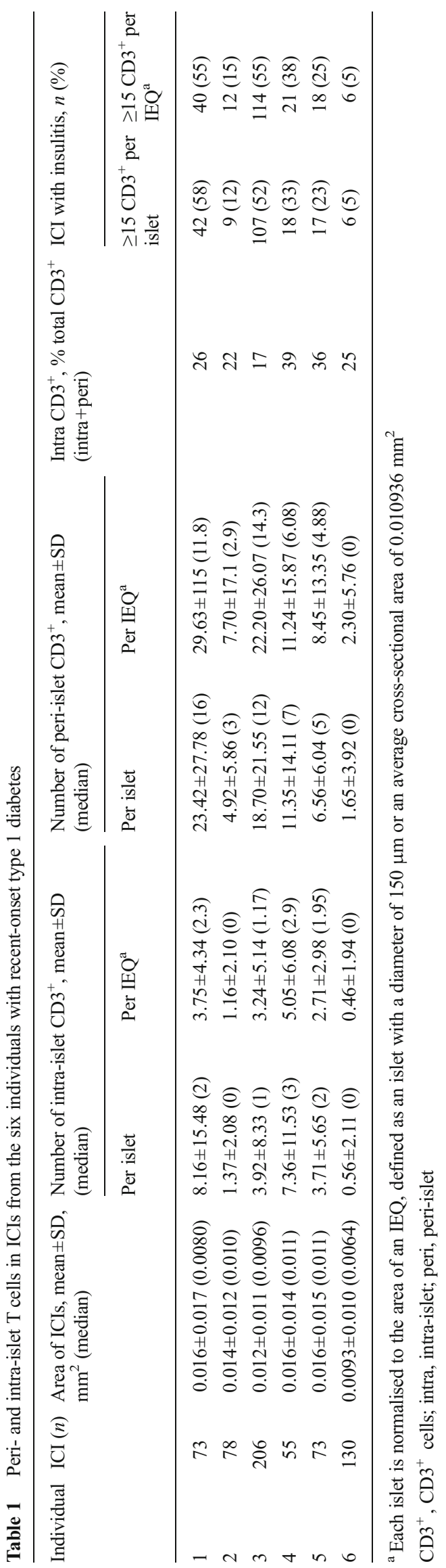




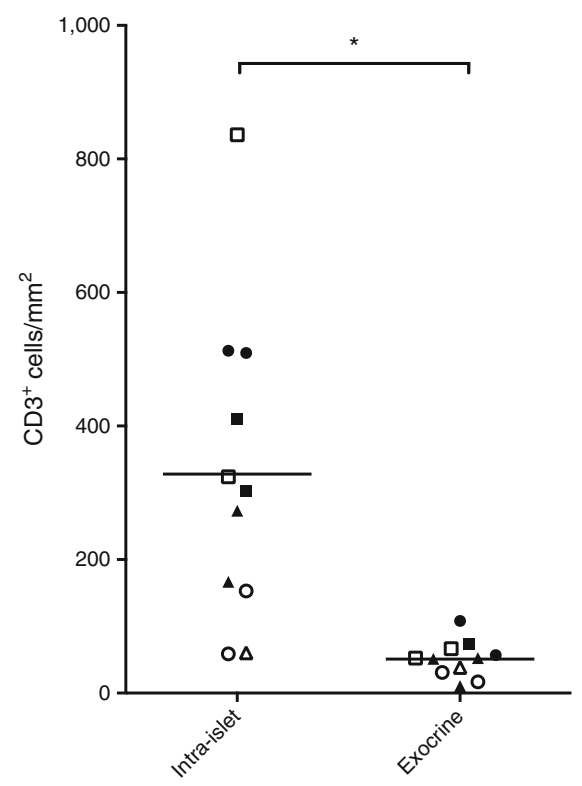

Fig. $2 \mathrm{CD}^{+}$cells per ICI (intra-islet) and exocrine area (excluding periislet $\mathrm{CD} 3$ ) in sections from individuals with recent-onset type 1 diabetes. Black circles, case 1; white circles, case 2; black squares, case 3 ; white squares, case 4; black triangles, case 5; and white triangles, case 6 . ${ }^{*} p<0.05$ calculated from the mean of two sections per patient

infiltrates in type 1 diabetic islets revealed a markedly different expression pattern (Fig. 5).

Cytokines and chemokines in isolated islets Luminex analysis of 41 cytokines and chemokines in isolated handpicked islets from the six type 1 diabetes patients showed signs of moderate inflammation, i.e. moderate levels of monocyte chemotactic protein 1 (MCP-1), IL-8, interferon $\gamma$ inducible protein 10 (IP-10) and CXC chemokines growth-regulated oncogene (GRO), that did not differ from isolated islets from braindead organ donors (Fig. 6a, b). Of the 41 analytes, 25 were above the detection limit in islets from at least one patient.
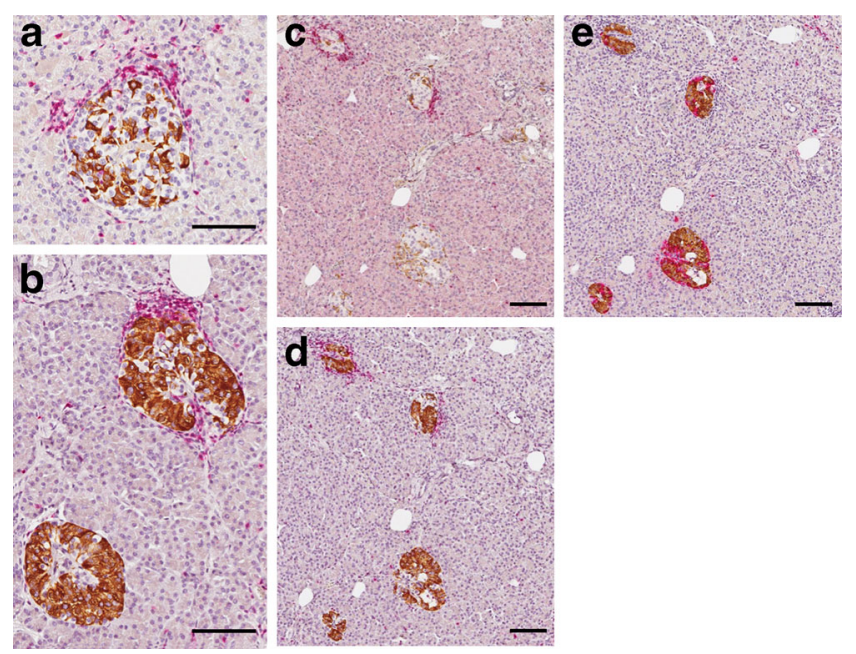

Fig. 4 Pancreatic tissue from individuals with type 1 diabetes stained for insulin (brown) and CD3 (red). (a) An islet with peri-insulitis in which the majority of $\mathrm{CD}^{+} \mathrm{T}$ cells are found in the islet-exocrine interface. (b) An apparently healthy islet (bottom) located next to an islet with intense periinsulitis (top). (c-e) Examples of the three different double stainings of the same area are shown: (c) CD3 red, glucagon brown; (d) CD3 red, insulin brown; and (e) glucagon red, insulin brown. Scale bar, $100 \mu \mathrm{m}$

Transcriptome data from the six type 1 diabetes patients and three non-diabetic controls confirmed that the expression of these 41 cytokines and chemokines was similar in the two groups (Fig. 6c, d).

\section{Discussion}

All six patients showed substantial intra- and peri-islet infiltration of $\mathrm{CD}^{+} \mathrm{T}$ cells. A majority of these islets contained insulin, whereas insulitis was seldom observed in IDIs. The number of $\mathrm{CD}^{+}$cells per islet varied greatly between individuals with type 1 diabetes despite the patients in this study being clinically homogeneous [9]. The cause of this variation
Fig. 3 Number of peri-islet (grey) and intra-islet (white) $\mathrm{CD}^{+}$cells per ICI in two pancreatic sections from each of the recent-onset type 1 diabetes cases. The total number of ICIs, the percentage ICI of all islets and the number and percentage of ICIs with insulitis are shown. Boxes, interquartile range; horizontal line, median; +, mean; and whiskers, maximum/ minimum

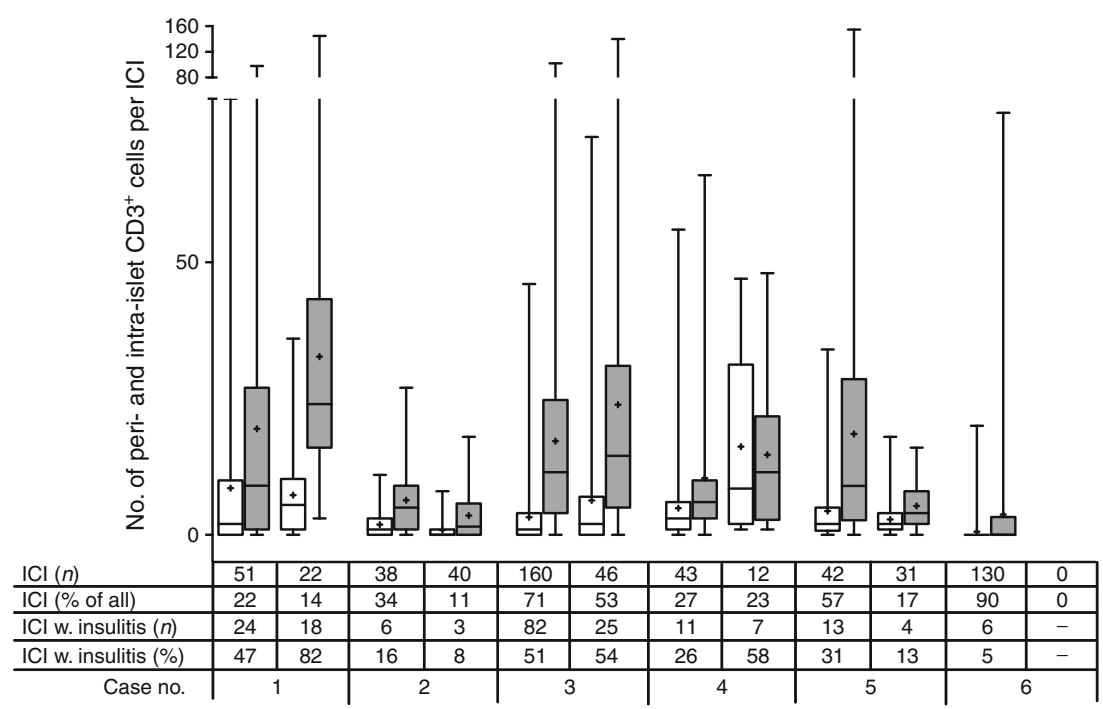


a

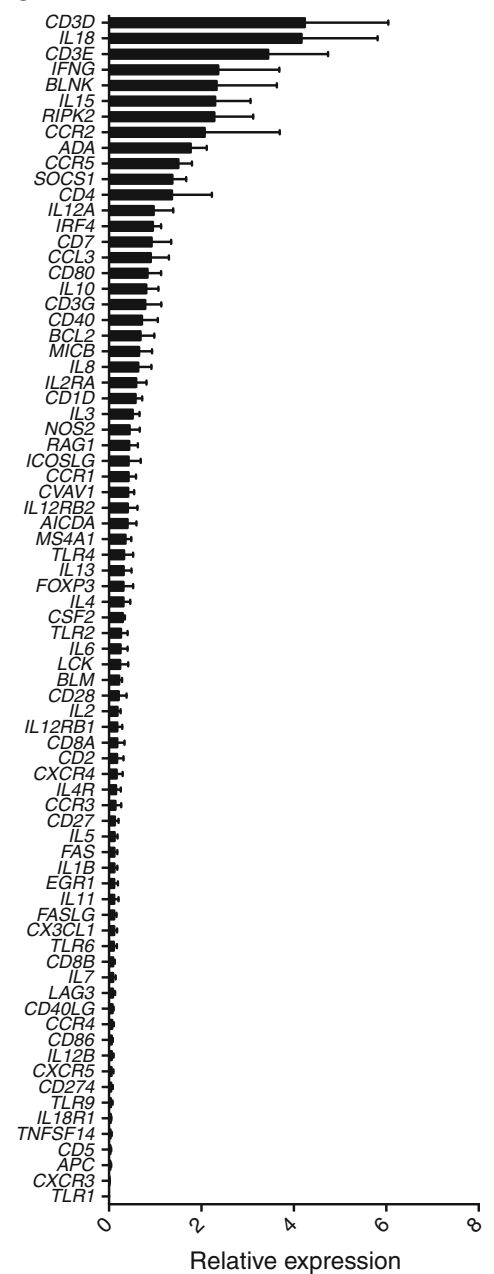

b

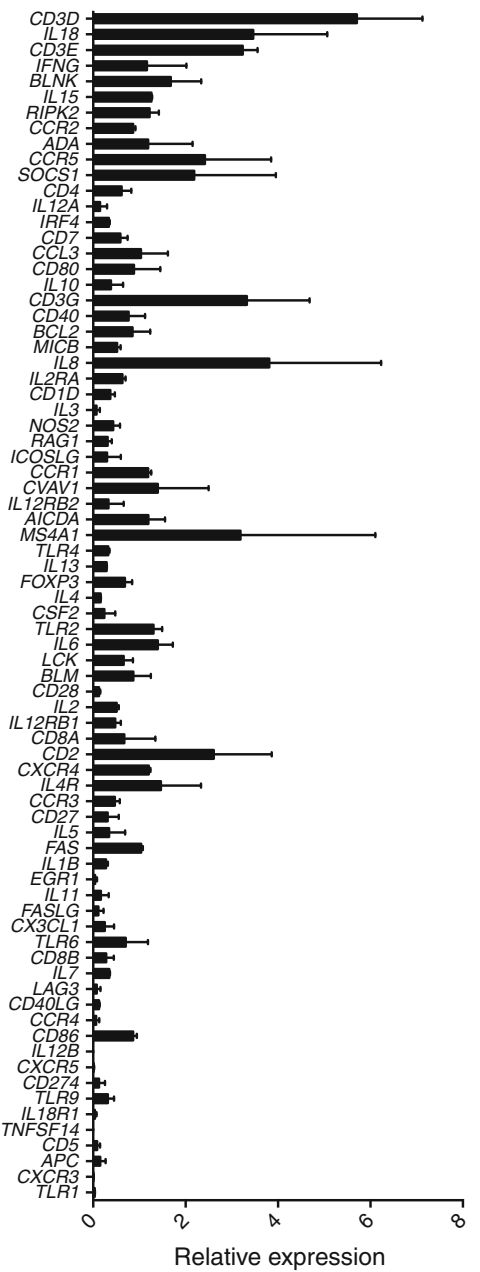

C

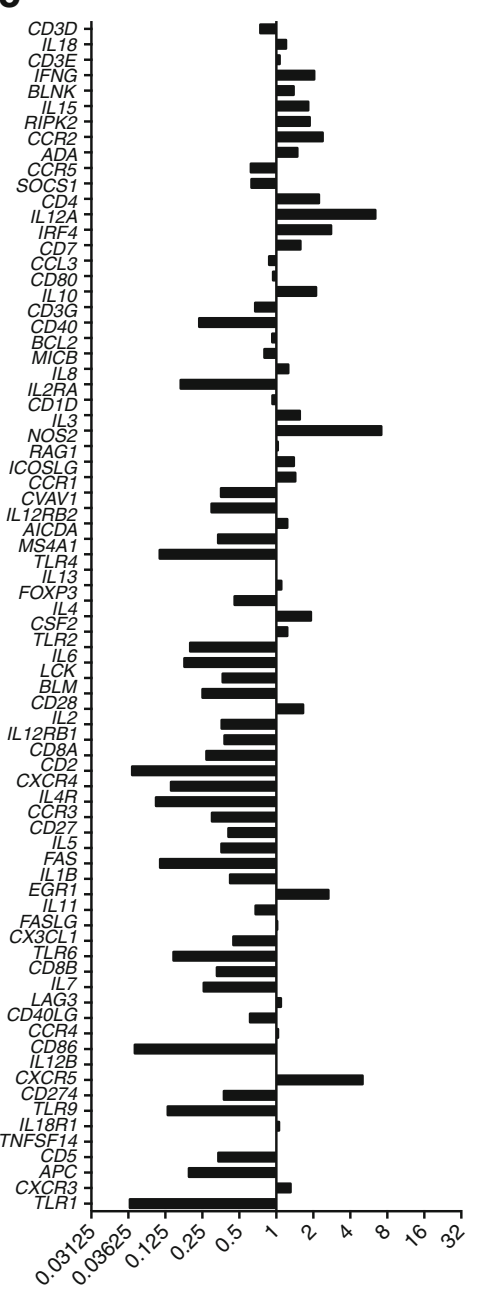

Expression ratio of islet / kidney infiltrate

Fig. 5 Expression of $\mathrm{T}$ and $\mathrm{B}$ cell genes in: (a) infiltrated pancreatic islets from six individuals with recent-onset type 1 diabetes; and (b) kidney biopsies from two cases with ongoing cell-mediated allorejection. (c)

is likely to be the previously described lobular pattern of disease progression with large variation between different pancreatic regions [16].

Notably, many islets contained insulin and seemed unaffected by the disease. Also, in some areas of the pancreatic biopsies the insulin-positive area was completely normal. This corresponds well with previous findings of focal and temporal distribution of the injurious inflammatory processes in type 1 diabetes [11]. Recent publications have shown that most patients with a long duration of type 1 diabetes continue to secrete low levels of endogenous insulin [17, 18], and our findings demonstrate that large numbers of insulin-positive, albeit perhaps dysfunctional, cells remain in individuals at the onset of type 1 diabetes. If disease progression could be halted, this beta cell volume would be of significant clinical importance.

The biopsies were collected shortly after diagnosis and when near-normoglycaemia had been re-established with exogenous insulin administration, precluding a potential
Expression ratio for islets/kidney (on a $\log _{2}$ scale). The expression of each gene is normalised to the expression of PTPRC (CD45)

influence of superimposed metabolic phenomena such as ongoing ketoacidosis or postmortem alterations on local conditions in the pancreas. The size of the resected specimen from the pancreatic tail allowed us to investigate several formalinfixed blocks from each patient, which is important as there is great variation in the presence of insulitis and other diseaserelated processes across the pancreas [16]. One major limitation of our study is the small number of cases examined compared with the larger number of autopsy cases that have been previously published [19]. Nevertheless, this study is, so far, the largest on well-preserved pancreatic tissue from individuals examined at onset of type 1 diabetes, allowing molecular characterisation that cannot be performed elsewhere. Also, our data may supplement the relatively limited cohort of recent-onset type 1 diabetes cases described previously $[5,16,19]$.

The prevalence of insulitis in the age group 15-39 years with duration of disease less than 1 month has been reported to be only $29 \%$ (5 of 17 cases) [19]. The higher prevalence of 
a

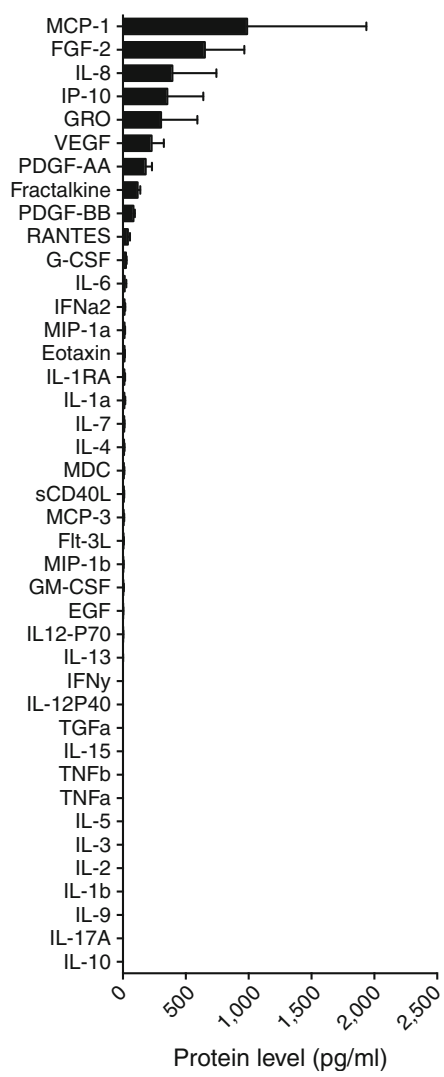

b

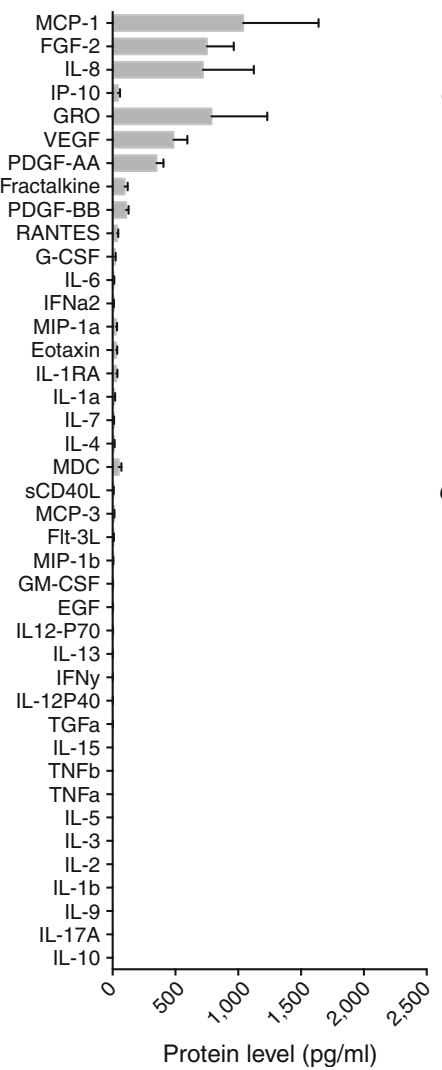

C

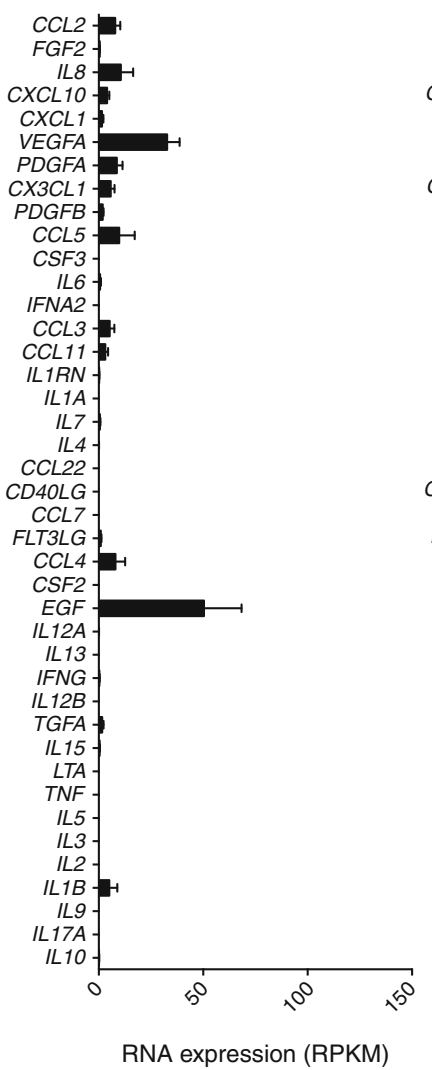

d

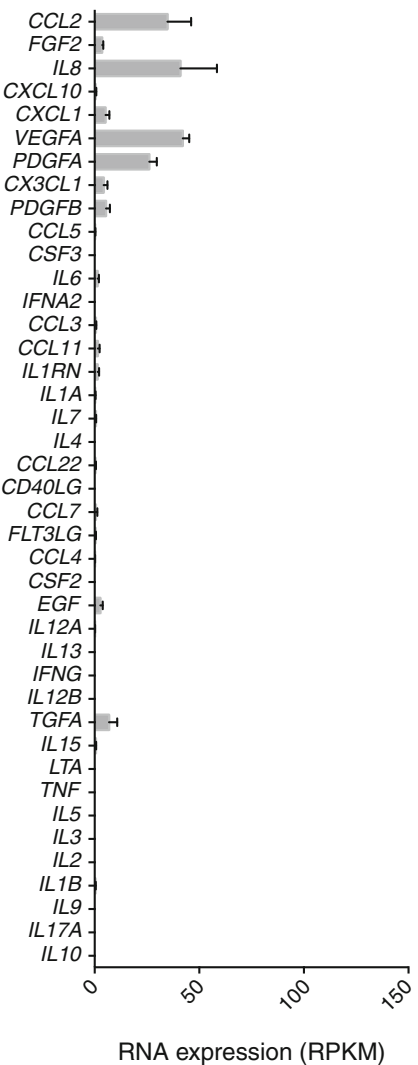

Fig. 6 Expression of cytokines and chemokines in isolated islets; proteins analysed by Luminex (a, b) and mRNA analysed by RNAseq (c, d). Data were collected from six cases with recent-onset type 1 diabetes $(\mathbf{a}, \mathbf{c})$ and from non-diabetic controls $(\mathbf{b}, \mathbf{d})$. See ESM Table 1 for full names of proteins

insulitis in children previously reported has led to speculation on whether the aetiology of type 1 diabetes is more heterogeneous in adults [20]. Our results indicate that the difference between children and adults may be overestimated, and that insulitis might be as frequent in at least young adults as in children [21]. This corresponds with the results in a thoroughly conducted study recently published that found insulitis in 11 out of 11 organ donors with type 1 diabetes, of whom five had disease duration of between 0.25 and 1.5 years [22].

A striking finding in this study is that the majority of isletassociated $T$ cells were located in the exocrine-endocrine interface, i.e. outside the actual islet parenchyma. The pathogenic role of these $\mathrm{T}$ cells is unclear, but as they are not in direct contact with the endocrine cells they are unlikely to bind to islet auto-antigens presented on HLA molecules on the beta cells. Previous studies using tetramer staining to detect T cells with reactivity to distinct beta cell auto-antigens show the presence of only occasional $\mathrm{T}$ cells, also located in the islet periphery [23]. Notably, the frequency of beta cell-specific $\mathrm{CD}^{+} \mathrm{T}$ cells in peripheral blood is similar in those with newly diagnosed type 1 diabetes and HLA-matched healthy controls [24]. The incapacity of the $\mathrm{CD} 8^{+} \mathrm{T}$ cells to invade the islet and mediate efficient beta cell lysis could potentially be explained by the extraordinarily weak affinity between the $T$ cell receptor (TCR) and the HLA class I presenting the postulated type 1 diabetes auto-antigen $[25,26]$. The TCR is abundant at such low levels of affinity and it was recently reported that they recognise more than a million different peptides presented on the appropriate HLA class I allele [27]. Drugs effective in preventing allograft rejection have been used in many intervention trials in type 1 diabetes with the assumption that the $\mathrm{T}$ cell-mediated destruction of beta cells resembles that of allograft rejection. Therefore, we chose to include a comparison of the T cells infiltrating the islets in type 1 diabetes with the $T$ cells mediating kidney rejection in transplanted patients. The findings reveal both qualitative and quantitative differences in $\mathrm{T}$ and $\mathrm{B}$ cell activation in the insulitic lesions in type 1 diabetes when compared with samples from individuals with ongoing allograft rejection (Fig. 5). The baseline cytokine/ chemokine expression in islets isolated from individuals with type 1 diabetes compared with islets from non-diabetic organ donors (Fig. 6) are in agreement with previous observations [23-27], and although the number of cases is small, suggests a different role of $\mathrm{T}$ cells in type 1 diabetes compared with $\mathrm{T}$ cells observed in allograft rejection. The role and function of $\mathrm{T}$ cells infiltrating the islets in type 1 diabetes warrants further investigation, and also comparison with $\mathrm{T}$ cells in other, more well-defined, conditions. 
It has recently been shown that, compared with nondiabetic controls, individuals with type 1 diabetes have an increased number of T cells in the peri-islet area [22] and the exocrine pancreas [28]. Their role in type 1 diabetes remains to be clarified: are they merely passive bystanders located in the inflamed peri-islet area? The role of these T cells needs to be urgently elucidated to obtain in-depth knowledge of the immunopathology of type 1 diabetes so that more efficient intervention therapies can be developed. Intervention trials in type 1 diabetes focusing on blocking T effector cells with drugs highly efficient at protecting an allograft have shown suboptimal protection of beta cell function: in the best situations, C-peptide production could be preserved temporarily and insulin requirements reduced, but no durable effects could be achieved [29-32].

Islets isolated from the type 1 diabetes patients expressed a number of chemokines (i.e. MCP-1, IL-8, IP-10 and GRO) involved in leucocyte recruitment, but the levels were not different from those expressed in islets isolated from braindead non-diabetic control donors, and were significantly lower, and with a much narrower repertoire, than demonstrated by Eizirik et al [33] in islets stimulated with IL-1 $\beta$ and IFN $\gamma$ (ESM Fig. 2). Whether $\mathrm{CD}^{+}$cells are present in these handpicked islets is unknown, and the isolation procedure itself can induce expression of some of these proteins. However, the low or absent expression of most of these chemokines and cytokines in islets from individuals with recent-onset type 1 diabetes described here fits well with the relatively low frequency of intra-islet $T$ cells and lack of signatures in the transcriptome analysis of activation (Fig. 6).

In conclusion, all the individuals with newly diagnosed type 1 diabetes enrolled in the DiViD study fulfilled the criteria for insulitis. Although it varied greatly, many islets contained insulin and several resembled completely normal islets, showing a significant reserve reservoir for insulin production. The islet-infiltrating T cells showed only background levels of cytokine/chemokine release and displayed marked differences at the messenger level when compared with allogeneic T cells.

Acknowledgements The authors thank: specialist nurse T. Roald, Oslo University Hospital, Norway, who provided invaluable efforts in coordinating the study; nurses and doctors at the local hospitals providing contact with the patients; and, finally, the patients who participated in this study. The authors also thank the Uppsala Genome Center and UPPMAX for assistance in massive parallel sequencing and computational infrastructure.

Funding The project was funded by South-Eastern Norway Regional Health Authority (Grant to KD-J), the Novo Nordisk Foundation (Grant to KD-J) and through the PEVNET Study Group funded by the European Union's Seventh Framework Programme (FP7/2007-2013) under grant agreement 261441 PEVNET. The participants of the PEVNET consortium are described at www.uta.fi/med/pevnet/publications.html. The work in Uppsala was supported by the Swedish Medical Research Council (VR K2011-65X-12219-15-6, K2015-54X-12219-19-4), the
Ernfors Family Fund, Barndiabetesfonden, the Swedish Diabetes Association, the Nordic Insulin Fund, the Diabetes Wellness foundation. Work performed at Uppsala Genome Center has been funded by RFI/VR 'SNISS' Swedish National Infrastructure for Large Scale Sequencing and Science for Life Laboratory, Uppsala. Human pancreatic biopsies and isolated islets were obtained from the Nordic Network for Clinical Islet Transplantation, supported by the Swedish national strategic research initiative Excellence of Diabetes Research in Sweden (EXODIAB) and the JDRF.

Duality of interest The authors declare that there is no duality of interest associated with this manuscript.

Contribution statement LK drafted the manuscript and was responsible for clinical coordination and the recruitment of patients and data collection, analysis and interpretation. AW was responsible for data analysis and interpretation of the results and participated in writing the manuscript. $\mathrm{BE}$ and $\mathrm{TB}$ made substantial contributions to the conception and design of the study, performed the surgery and participated in writing the manuscript. FLJ, EL, KFH and OK contributed to the study design, data analysis and interpretation and writing the manuscript. OS drafted the manuscript and participated in study design, data collection and analysis and interpretation of the results. KD-J was the principal investigator of the study, had the initial idea for the DiViD study, and participated in the study design, funding, regulatory issues, international collaboration, data collection, analysis and interpretation, and writing the manuscript. LK and KD-J are the guarantors of this work and, as such, had full access to all the data in the study and take responsibility for the integrity of the data and the accuracy of the data analysis. All authors had final approval of the version to be published.

\section{References}

1. Eisenbarth GS (1986) Type I diabetes mellitus. A chronic autoimmune disease. N Engl J Med 314:1360-1368

2. Atkinson MA (2012) The pathogenesis and natural history of type 1 diabetes. Cold Spring Harb Perspect Med 2:1-18

3. Matveyenko AV, Butler PC (2008) Relationship between beta-cell mass and diabetes onset. Diabetes Obes Metab 10(Suppl 4):23-31

4. Klinke DJ (2011) Age-corrected beta cell mass following onset of type 1 diabetes mellitus correlates with plasma C-peptide in humans. PLoS One 6:e26873

5. In't Veld P (2014) Insulitis in human type 1 diabetes: a comparison between patients and animal models. Semin Immunopathol 36: 569-579

6. Schmidt MB (1902) Ueber die beziehung der Langerhanschen inseln des pankreas zum diabetes mellitus. Munch Med Wochenschr 49:51-54, article in German

7. Von Meyenburg M (1940) Ueber "insulitits" bei diabetes. Schweiz Med Wochenschr 21:554-557, article in German

8. Campbell-Thompson ML, Atkinson MA, Butler AE et al (2013) The diagnosis of insulitis in human type 1 diabetes. Diabetologia 56:2541-2543

9. Krogvold L, Edwin B, Buanes T et al (2014) Pancreatic biopsy by minimal tail resection in live adult patients at the onset of type 1 diabetes: experiences from the DiViD study. Diabetologia 57:841-843

10. Krogvold L, Edwin B, Buanes T et al (2015) Detection of a lowgrade enteroviral infection in the islets of Langerhans of living patients newly diagnosed with type 1 diabetes. Diabetes 64:1682-1687 
11. Foulis AK, Liddle CN, Farquharson MA, Richmond JA, Weir RS (1986) The histopathology of the pancreas in type 1 (insulindependent) diabetes mellitus: a 25 -year review of deaths in patients under 20 years of age in the United Kingdom. Diabetologia 29:267274

12. Marselli L, Sgroi DC, Bonner-Weir S, Weir GC (2009) Laser capture microdissection of human pancreatic beta-cells and RNA preparation for gene expression profiling. Methods Mol Biol 560:87-98

13. Skog O, Korsgren S, Wiberg A et al (2015) Expression of human leukocyte antigen class I in endocrine and exocrine pancreatic tissue at onset of type 1 diabetes. Am J Pathol 185:129-138

14. Korsgren S, Molin Y, Salmela K, Lundgren T, Melhus A, Korsgren O (2012) On the etiology of type 1 diabetes: a new animal model signifying a decisive role for bacteria eliciting an adverse innate immunity response. Am J Pathol 181:1735-1748

15. Goto M, Eich TM, Felldin M et al (2004) Refinement of the automated method for human islet isolation and presentation of a closed system for in vitro islet culture. Transplantation 78:1367-1375

16. Gepts W (1965) Pathologic anatomy of the pancreas in juvenile diabetes mellitus. Diabetes 14:619-633

17. Oram RA, Jones AG, Besser RE et al (2014) The majority of patients with long-duration type 1 diabetes are insulin microsecretors and have functioning beta cells. Diabetologia 57:187-191

18. Keenan HA, Sun JK, Levine J et al (2010) Residual insulin production and pancreatic ss-cell turnover after 50 years of diabetes: Joslin Medalist Study. Diabetes 59:2846-2853

19. In't Veld P (2011) Insulitis in human type 1 diabetes: the quest for an elusive lesion. Islets 3:131-138

20. Pipeleers D, Ling Z (1992) Pancreatic beta cells in insulindependent diabetes. Diabetes Metab Rev 8:209-227

21. Gale EA (2001) The discovery of type 1 diabetes. Diabetes 50:217-226

22. Reddy S, Zeng N, Al-Diery H et al (2015) Analysis of peri-islet CD45-positive leucocytic infiltrates in long-standing type 1 diabetic patients. Diabetologia 58:1024-1035

23. Coppieters KT, Dotta F, Amirian N et al (2012) Demonstration of islet-autoreactive CD8 T cells in insulitic lesions from recent onset and long-term type 1 diabetes patients. J Exp Med 209:51-60
24. Skowera A, Ladell K, McLaren JE et al (2015) Beta-cell-specific CD8 $\mathrm{T}$ cell phenotype in type 1 diabetes reflects chronic autoantigen exposure. Diabetes 64:916-925

25. Bulek AM, Cole DK, Skowera A et al (2012) Structural basis for the killing of human beta cells by CD8(+) T cells in type 1 diabetes. Nat Immunol 13:283-289

26. Abreu JR, Martina S, Verrijn Stuart AA et al (2012) CD8 T cell autoreactivity to preproinsulin epitopes with very low human leucocyte antigen class I binding affinity. Clin Exp Immunol 170:57-65

27. Wooldridge L, Ekeruche-Makinde J, van den Berg HA et al (2012) A single autoimmune $T$ cell receptor recognizes more than a million different peptides. J Biol Chem 287:1168-1177

28. Rodriguez-Calvo T, Ekwall O, Amirian N, Zapardiel-Gonzalo J, von Herrath MG (2014) Increased immune cell infiltration of the exocrine pancreas: a possible contribution to the pathogenesis of type 1 diabetes. Diabetes 63:3880-3890

29. Staeva-Vieira T, Peakman M, von Herrath M (2007) Translational mini-review series on type 1 diabetes: immune-based therapeutic approaches for type 1 diabetes. Clin Exp Immunol 148:17-31

30. Pescovitz MD, Greenbaum CJ, Krause-Steinrauf H et al (2009) Rituximab, B-lymphocyte depletion, and preservation of beta-cell function. N Engl J Med 361:2143-2152

31. Keymeulen B, Walter M, Mathieu C et al (2010) Four-year metabolic outcome of a randomised controlled CD3-antibody trial in recent-onset type 1 diabetic patients depends on their age and baseline residual beta cell mass. Diabetologia 53:614-623

32. Herold KC, Gitelman S, Greenbaum C et al (2009) Treatment of patients with new onset type 1 diabetes with a single course of anti$\mathrm{CD} 3 \mathrm{mAb}$ Teplizumab preserves insulin production for up to 5 years. Clin Immunol 132:166-173

33. Eizirik DL, Sammeth M, Bouckenooghe T et al (2012) The human pancreatic islet transcriptome: expression of candidate genes for type 1 diabetes and the impact of pro-inflammatory cytokines. PLoS Genet 8, e1002552 